\title{
Empirical Study of the Coupling Relationship Between Biodiversity and Environmental Geology Under Different Ecological Status: Evidence From Five Typical Areas in Guizhou, China
}

\section{Yuangui Xie}

Guizhou University

Lanyue Zhang

Guizhou Academy of Sciences

Xinxiang Gong

land mineral resources reserve bureau of guizhou privince

Jiming Liu ( $\sim 296392800 @ q q . c o m$ )

Guizhou University

Xiaofeng Liao

Guizhou Academy of Sciences

Yanyan Dong

Guizhou Academy of Sciences

\section{Research Article}

Keywords: Biodiversity, Environmental geology, Coupling degree, Human activities, Karst

Posted Date: October 18th, 2021

DOl: https://doi.org/10.21203/rs.3.rs-937603/v1

License: (c) (1) This work is licensed under a Creative Commons Attribution 4.0 International License.

Read Full License

Version of Record: A version of this preprint was published at Environmental Science and Pollution Research on March 4th, 2022. See the published version at https://doi.org/10.1007/s11356-022-18878-9. 
1 Empirical study of the coupling relationship between biodiversity and environmental geology under different ecological status: Evidence from five

\section{typical areas in Guizhou, China}

Yuangui Xie ${ }^{1,2}$ Lanyue Zhang ${ }^{2}$, Xingxiang Gong ${ }^{3}$, Jiming Liu ${ }^{1 *}$, Xiaofeng Liao², and Yanyan Dong²

${ }^{1}$ College of Forestry, Guizhou University, Guiyang 550000, People's Republic of China

${ }^{2}$ Institute of Mountain Resources, Guizhou Academy of Sciences, Guiyang 550000, People's Republic of China

${ }^{3}$ Land Mineral Resources Reserve Bureau of Guizhou Province, Guiyang 550000, People's Republic of China

Corresponding author's email address: karst0603@163.com

Note: I have not submitted my manuscript to a preprint server before submitting it to Environmental Science and Pollution Research.

\section{Declarations:}

-Ethical Approval: Not applicable

-Consent to Participate: Not applicable

-Consent to Publish: Not applicable

-Authors Contributions: All authors contributed to the study conception and design. Material preparation, data collection and analysis were performed by YX, XG, JL, XL and YD. The first draft of the manuscript was written by $\mathrm{LZ}$ and all authors commented on previous versions of the manuscript. All authors read and approved the final manuscript.

-Competing Interests: The authors declare that they have no competing interests.

-Availability of data and materials: The datasets used and/or analyzed during the current study are 
available from the corresponding author on reasonable request.

\section{Abstract}

Analyzing the coupling relationship between biodiversity and environmental geology and exploring the factors affecting the coupling degree are of vital significance for the protection and restoration of the ecological environment. In this study, we selected five typical areas (i.e., Caohai, Chishui, Fanjingshan, Maolan, and Guanshanhu) to represent the whole Guizhou Province, China. Based on the coupling coordination degree model, we analyzed their coupling coordination trend. The results showed that the coordinated development stages of the Chishui and Fanjingshan areas both could be categorized as the synchronous development type of primary coordination because of their excellent nature conditions; the Maolan area was categorized as having restrained environmental geology because of its weak environmental geology condition; and the Guanshanhu and Weining areas were strongly affected by human activities, and both could be categorized as having restrained biodiversity. In combination with practical situation, Guizhou province can be categorized into the following three zones: an original ecological zone, a zone with fragile ecological environment, and a zone affected by human activities. Biodiversity conservation measures should be proposed according to the specific ecological situation of these different zones. In this way, the harmonious coexistence of economic development and the ecological environment can be realized.

\section{Keywords: Biodiversity; Environmental geology; Coupling degree ; Human activities; Karst}

\section{Introduction}

Biodiversity is the cornerstone of human survival and development, and its conservation is a major issue humankind jointly faces. Biodiversity conservation closely relates to human well-being in 
the present and in future, and it holds great significance for the construction of an ecological civilization and the sustainable development of society. Spatial heterogeneity of geomorphology and diversity of geological conditions directly affect the habitats of all creatures, which form the premise and basis of biodiversity (Liu et al. 2008, Huang et al. 2019). Because of differences in natural conditions, such as climate, topography, geological structure, karstification, and soil, different interaction processes of geological and geomorphological systems, hydrological and soil systems, and vegetation and ecological niche systems occur at different spatial scales. Different karst ecosystems with different system structures have special functions and coupling effects as well as different background stabilities and fragilities, thus creating different types of habitats (Jiang et al. 2020, Dong et al. 2008, Wang 2013, Lei et al. 2020). In addition to these natural factors, the influence of human factors on biodiversity cannot be ignored. Human beings are an integral part of the natural environment. With the advanced development of human society, human activities have become a stable factor affecting the natural environment of various circles on Earth, including the atmosphere, pedosphere, and lithosphere (Wilson and Ehrlich 1991). When human beings excessively pursue economic development, a large share of natural resources is consumed, causing serious damage to surface vegetation and leading to rapid loss of species' habitats (Wilson and Ehrlich 1991, Cuomo et al. 2001, Gosselin and Callois 2018).

understanding the origin and maintenance of mountainous biodiversity (Hu et al. 2020). Many scholars have conducted in-depth research on this topic. Several scholars have studied the relationship between geology and biodiversity from the perspective of mountain structure—-for example, how environmental and biological processes have shaped mountainous biodiversity (Huang et al. 2019, Antonelli et al. 
2018). A number of scholars also have studied the influence of a single factor on biodiversity - for example, how temperature, rainfall, and soil affect biodiversity (Ott 2020). Other scholars have studied the influence of the pedogenic rock-soil-water system on biodiversity (by emphasizing plant growth) from the perspective of the geochemical background (Jiang et al. 2020). This study comprehensively evaluated the two systems of biodiversity and environmental geology and analyzed the coupling relationship between them.

Guizhou Province is characterized by numerous karst geological formations (Jiang et al. 2020). Its unique geographical climate, karst geology, and landform provide good breeding spaces and living conditions for numerous biological resources, endowing the region with a high degree of biodiversity (Zhao et al. 2011, Wang et al. 2014). In addition to the rapid development of economy and society in Guizhou, the increasing population pressure, the expanding human activity scope, the unreasonable and excessive use of resources, and the fragility of the ecological environment in the karst region jointly have caused the destruction and functional degradation of this environment. This also has led to the rapid loss of natural habitats. Native species are subject to an increasing threat, and invasive species can tip the ecological stability. These ecological problems are the main reasons for the continuous decline of biodiversity in Guizhou Province (Zhao et al. 2011, Wang et al.2014, Liu et al. 2019).

This study selected five typical areas in Guizhou Province (i.e., Caohai, Chishui, Fanjingshan, Maolan, and Guanshanhu) to analyze the coupling relationship between biodiversity and environment geology based on the comprehensive index model and the coupling coordination degree model. The results provide a decision-making basis for regional biodiversity conservation, territorial spatial planning and control, and the protection and restoration of the ecological environment. 


\section{Research area and data sources}

\subsection{Research area}

On the basis of considerations of the environmental geological conditions and the distribution characteristics of biodiversity, we selected five representative areas in Guizhou Province as research areas, as shown in Table 1 and Figure 1. The topography in Guizhou Province is higher in the west and lower in the east, which has a roughly three ladder-like distribution. The average elevation of the first step is above $1500 \mathrm{~m}$ while the third step is below $800 \mathrm{~m}$. These research areas cover the three steps and the northern and southern slopes (Zhou 2000). In terms of stratigraphic lithology, the research areas feature the main rock types found in this province, including metamorphic rocks, terrigenous detrital rocks, and carbonate rocks (dolomite and limestone). The research areas also feature the main ecosystem types found in this province, including lakes, deep forests, mountains, and towns (Figure 2). In terms of biodiversity, four of the five research areas are located in the nature reserves of Guizhou Province, which are extremely important for biodiversity conservation with regard to provincial functional area planning and national planning.

\subsection{Data sources}

The data that form the basis of this study mainly included topography, geological structure, hydrogeology, and biodiversity data. We obtained the data for the digital elevation model (DEM) from the geo-spatial data cloud (http://www.gscloud.cn/), at a resolution of $30 \mathrm{~m}$. Geographic information system (GIS) technology was applied for geometric correction, image stitching, image mosaic, and projection transformation. We extracted geographical indexes, such as slope gradient, slope aspect, and surface relief. In addition, we integrated the spatial resolution and projection. The geological structure data, the stratigraphic data, the hydrogeological data, the soil investigation data and human activities 
data were obtained from Land Mineral Resources Reserve Bureau of Guizhou Province. Biodiversity data were obtained from field investigations (shown as Table 2) and normalized difference vegetation index (NDVI) data. The NDVI data were obtained at no cost from the SPOT_VGT website (https://proba-v.vgt.vito.be/en). The monthly NDVI was generated from 10 days of NDVI data using the maximum value composite method.

\section{Research methods}

\subsection{Establishment of the indicator system}

According to the principles of operability, scientificity, systematicness, and comprehensiveness, we selected the representative indicators to characterize biodiversity and environmental geology. In detail, we selected 11 indicators to characterize biodiversity, including ecosystem richness (x1), net primary productivity (x2), vegetation coverage (x3), naturalness (x4), urbanization rate (x5), importance of the maintenance function of biodiversity (x6), richness of wild vascular plants (x7), wild animal richness (x8), species endemism (x9), threatened species richness (x10), and the degree of alien species invasion (x11). We divided the indicators that characterize the environmental geology into two categories: natural conditions and human activities, which involved 19 and 7 indicators, respectively. The indicators of natural conditions included geomorphic type (y1), slope gradient (y2), slope aspect (y3), earth surface relief (y4), lithology (y5), rock exposure degree (y6), stratigraphy (y7), engineering geological characteristics of the rock mass (y8), importance of water conservation function (y9), importance of soil and water conservation function (y10), groundwater buried depth (y11), water abundance of water-containing rock formations (y12), water resource richness (y13), main soil types (y14), soil profile constitution (y15), soil layer thickness (y16), main topsoil texture (y17), soil nutrient content (y18), and soil pH value (y19). The indicators of human activities included karst flood (y20), 
133

karst drought (y21), water resource depletion (y22), soil and water loss (y23), rocky desertification (y24), groundwater pollution (y25), and over standard of soil elements (y26). Then, we used the Delphi method to construct a grading standard for the established evaluation indicators and to determine the corresponding grading index.

\subsection{Analysis of indicator weights}

In this study, we determined indicator weights using a combination of the subjective method (i.e., the Delphi method) and the objective methods (i.e., the standard deviation method and the entropy value method). When the objective method was used, we took the average value of the "standard deviation method" and "entropy value method" as the final value. Then, we processed the two values obtained from the subjective method and the objective method according to the multiplier synthesis method to calculate the weight value of a certain indicator. Finally, we normalized this weight value using the range method to obtain the final comprehensive weight value of the indicator (Wang and Song 2003). The calculation formula follows:

$$
\theta i=\prod_{j=1}^{k} \omega_{i}(j) / \sum_{i=1}^{m} \prod_{j=1}^{k} \omega_{i}(j)
$$

where $\omega_{\mathrm{i}}(\mathrm{j})$ represents the weight of the $i$-th indicator obtained by the $j$-th weighting method; $\theta_{1}$ represents the comprehensive weight after normalization processing; $j=1,2,3, \ldots, k$; and $i=1,2$, $3, \ldots, m$

\subsection{Comprehensive index function}

Assuming that $f$ and $g$ represent biodiversity and environmental geological system, respectively, and that $f(x)$ and $g(y)$ are functions that measure their development levels, respectively (Xiong et al. 2014, Qian et al. 2018), the comprehensive index function of biodiversity follows: 


$$
f(x)=\sum_{i=1}^{m} \theta_{i} X_{i}
$$

The comprehensive index function of the environmental geological system is given by

$$
\mathrm{g}(y)=\sum_{j=1}^{n} \theta_{j y_{j}},
$$

where $\theta_{i}$ and $\theta_{\mathrm{J}}$ represent the comprehensive weights of biodiversity and environmental geological indicators, respectively; $\mathrm{X}_{i}$ and $\mathrm{y}_{j}$ are the normalized values of original indicators of biodiversity and environmental geology, respectively. The extreme value method was applied for normalization.

\subsection{Measures for coupling coordination between biodiversity and environmental geology}

The coupling degree of biodiversity and environmental geology was measured by the coupling coordination degree model. It can be calculated with the following formula (Xiong et al. 2014, Qian et al. 2018):

$$
C=\left\{\frac{\mathrm{f}(x, \mathrm{t}) \times g(y, t)}{[\mathrm{f}(x, t)+g(y, t)]^{k}}\right\}^{\frac{1}{k}},
$$

where $C$ represents the coupling degree value, with the range of [0,1]; the larger the value of $C$, the stronger the interaction between the two systems; $k$ is the adjustment coefficient, which takes the value of 2 because it involves two systems.

The coupling degree value emphasizes the interaction between systems, which can reflect the consistency degree of several systems developing as a whole. It disregards, however, the interactions between the elements of different systems and between the internal elements within a system. Because the interaction relationship and coordination degree between the elements of different regions differ, we introduced the coordination degree model to describe the interaction relationship among these elements.

Its calculation formulas are as follows:

$$
D=\sqrt{C \bullet T}
$$




$$
T=\alpha \mathrm{f}(x, \mathrm{t})+\beta g(y, t),
$$

where $D$ represents the coordination degree of biodiversity and environmental geology, with the range of $[0,1]$; the greater the value of $D$, the better the coordination degree of the two systems; $C$ represents the coupling degree between biodiversity and environmental geology; $T$ represents the comprehensive level of biodiversity and environmental geology; and $\alpha$ and $\beta$ are undetermined coefficients. Considering the current importance degree of biodiversity and environmental geology, we assumed that biodiversity protection is an important reflection of the ecological civilization construction in a nation.

Hence, the biodiversity system should have a higher weight than the environmental geological system. For this paper, we assumed that $\alpha=0.6$ and $\beta=0.4$.

According to the relevant literature, the evaluation criteria of coupling degree and coordination degree are presented in Table 3 and Table 4, respectively (Zhang et al. 2018).

\section{Results and analysis}

\subsection{Analysis of the comprehensive index function}

On the basis of Eqs. (2) and (3), we calculated the comprehensive indexes of biodiversity and environmental geology. The results are shown in Figure 3.

As shown in Figure 3, the comprehensive index values of biodiversity in the five research areas have the following order: Guanshanhu $(0.14)<$ Weining $(0.34)<$ Maolan $(0.65)<$ Chishui $(0.79)<$ Fanjingshan (0.81). The comprehensive biodiversity indexes of the Chishui and Fanjingshan research areas were significantly higher than those of the Guanshanhu and Weining research areas. The Guanshanhu and Weining research areas are both located in urban construction areas with high urbanization rates; therefore, their biodiversity has been greatly affected by human activities. Human disturbance significantly disrupts species composition and directly affects the succession processes of 
197

plant communities (Bardgett and Putten 2014, Williams et al. 2020). In contrast, the Chishui and Fanjingshan research areas are both located in nature reserves with good ecological conditions, and their biodiversity is rarely affected by human activities. The Maolan research area is largely covered by primary karst forests, including three typical topographies (i.e., trough valley, funnel, and sloping land) (Lang and Long 2012). Although the Maolan research area is rich in ecological niches, the vegetation coverage is lower than in the Fanjingshan and Chishui research areas (Ott 2020); hence, the comprehensive index of biodiversity is also lower than those of these two research areas.

The comprehensive index values of environmental geology have the following order: Weining $(0.47)<$ Maolan $(0.48)<$ Guanshanhu $(0.60)<$ Chishui $(0.67)<$ Fanjingshan $(0.79)$. The Weining and Guanshanhu research areas are both located in urban construction areas, where human activities have greatly influenced the environmental geology. Along with continuous economic and social development, new geological and environmental problems are constantly emerging (Sheng et al. 2015); therefore, their comprehensive index of environmental geology is low. The Maolan research area is a typical karst landform area. Its unique binary landform structure often produces the phenomena of "high mountains and low waters," "more rain and more drainage," and "more rocks and less soil," as well as "poor soil and easy drought." The Maolan research area has many environmental and geological problems, including soil erosion and rocky desertification (Lang and Long 2012, Li et al. 2004). Therefore, the comprehensive index value of the environmental geology is relatively low. The Fanjingshan and Chishui research areas have stable geomorphic structures and good ecological situations and are less affected by human activities; therefore, their comprehensive indexes of environmental geology are maximal.

The comparison of the comprehensive index values of biodiversity and environmental geology of 
each research area showed that the biodiversity comprehensive indexes of the Chishui, Fanjingshan, and Maolan research areas were larger than the environmental geology comprehensive indexes. Additionally, the development status of these areas could be categorized as the environmental geology restrained type. In contrast, the development status of the Guanshanhu and Weining research areas could be categorized as the biodiversity restrained type. The Chishui, Fanjingshan, and Maolan research areas are located in nature reserves with excellent ecological conditions and rich biodiversity, whereas the Guanshanhu and Weining research areas are located in urban construction areas, where the biodiversity has been greatly affected by human activities.

\subsection{Coupling degree and coordination degree analysis}

\subsubsection{Coupling degree analysis}

As shown in Figure 4, even in the Fanjingshan and Chishui research areas with their excellent ecological and geological conditions, the coupling degree reached only about 0.5 . This value indicated that although a certain correlation between biodiversity and environmental geology exists, this correlation is weak. Many factors affect biodiversity, and the environmental geological conditions are but part of the causes. In future, related studies should investigate the influences of other factors in other fields (e.g., climatic conditions) on biodiversity.

\subsubsection{Coordination degree analysis}

The coordination degree can reflect the relative development status of the two systems. The results showed that the coordination degrees of the five research areas (from small to large) follow the order of Guanshanhu $(0.36)<$ Weining $(0.44)<$ Maolan $(0.54)<$ Chishui $(0.61)<$ Fanjingshan $(0.63)$, which was the same as the order of the biodiversity comprehensive indexes. The coordination degrees of Guanshanhu and Weining research areas were the lowest, as their biodiversity has been damaged by 
241

human activities, leading to poor coordination degrees of these two systems. The Fanjingshan and

Chishui research areas had the highest coordination degrees, indicating that these two systems are in a good stage of coordinated development. The coordination degree of the Maolan research area was lower than that of Fanjingshan and Chishui research areas, because of the poor environmental geology in Maolan research area.

\subsection{Analysis of coupling and coordinated development stages}

According to the evaluation criteria, we obtained the coupling types, coordination levels, and coordinated development types of biodiversity and environmental geology in the research areas. The results are presented in Table 5.

Table 5 shows that the coupling types of the five research areas are at the antagonistic stage (the coupling degree analysis explained this result). The Guanshanhu and Weining research areas are at the level of near non-coordination, because they have been greatly affected by human activities. Human activities not only directly damage biodiversity but also indirectly produce negative influences on the biodiversity by damaging the environmental geology. Hence, it is necessary to focus on these two research areas and initiate powerful regulation and protection measures. Generally, the biodiversity could be effectively protected by locally limiting human activities. The Chishui, Fanjingshan, and Maolan research areas are at the level of primary coordination. To maintain the coordination development status of these areas, it is necessary to strengthen the protection of biodiversity and environmental geological systems.

In the Chishui and Fanjingshan research areas, with their good ecological and environmental geological conditions, the coordinated development type can be classified as synchronous development of primary coordination. This indicates that their biodiversity and environmental geological systems 
have developed synchronously, with no restraint in either system. The coordinated development type of the Maolan research area can be classified as restrained environmental geology. Therefore, protecting the environmental geology should be emphasized to promote the synchronous development of environmental geology and biodiversity in this area. The Guanshanhu and Weining research areas have been greatly affected by human activities, and their coordinated development types can be classified as restrained biodiversity. For the protection of biodiversity and environmental geology, relevant control measures should be initiated to limit human activities and promote the protection of local biodiversity.

\section{Discussion}

According to the results for the five investigated research areas, the Fanjingshan and Chishui research areas had the highest biodiversity comprehensive indexes, environmental geology comprehensive indexes, and coupling/coordination degrees. Moreover, their coupling and coordinated development situations of the biodiversity system and environmental geological system were also the best. The Guanshanhu and Weining research areas had the lowest values, and their coupling and coordinated development situations of the biodiversity system and environmental geological system were the worst. The Maolan research area was an exception because of its weak environmental geology.

The Fanjingshan and Chishui research areas have rich biodiversity and high vegetation coverage. In addition, their original environment has been well preserved and has been barely affected by human disturbance, and no eco-geological problems have occurred. Therefore, all of the estimated values of these two research areas were the highest among the five research areas, and the two systems of biodiversity and environmental geology have developed synchronously. The Fanjingshan research area is located to the west of the Fanjingshan National Nature Reserve, which has been recognized as the 
best protected primeval forest in the world. The ancient stratum formed 1-1.4 billion years ago and is home to a variety of organisms. The complex terrain and diverse ecological environments of Fanjingshan endow its typical forest characteristics with diverse forest types, rich plant species, and numerous rare and ancient relic plants (Chen et al. 2020). The dense forests and various food resources for animals, such as plants, flowers, and fruits, as well as the excellent hydrological and ecological environments of Fanjingshan provide a superior habitat for inhabiting, moving, foraging, and breeding of wild animals. Therefore, complex and diverse food chains have formed with the distribution of a large number of wild animals (Cai et al. 2020, Guo et al. 2020). The Chishui research area is located in the Suoluo National Nature Reserve and its surrounding area. The special regional location and the long-term evolution of geology, geomorphology, and ecology have facilitated the formation of warm and moist climatic conditions, which have improved the ecological background. Hence, this is a desirable habitat for a variety of species as well as an ideal refuge for rare species, which has resulted in the region's rich biodiversity (Yu et al. 2015).

The Maolan research area is a typical karst landform area with poor natural environmental geology conditions but with rich biodiversity. Its comprehensive biodiversity index is high, whereas the comprehensive index of its environmental geology is low (ranging between the estimated values of the Weining and Guanshanhu research areas). Therefore, the environmental geological system has lagged behind the biodiversity system. The Maolan research area is located to the west of the Maolan National Nature Reserve. It is the best protected karst forest ecosystem with the largest remaining area and the most concentrated distribution of karst landforms in the same latitude on Earth. Furthermore, it has a strong primordial nature and relatively good stability. In addition to a small amount of cane thorn shrub and shrub tussock, the natural vegetation of this ecosystem mainly consists of primordial evergreen and 
deciduous broad-leaved mixed forest growing on the karst landform, which is a type of zonal vegetation ( $\mathrm{Wu}$ et al. 2019). This research area has well-preserved forest vegetation, diverse habitats, and special environments, making it an important habitat for many wild animals. In terms of environmental geology, the exposed area of carbonate rocks is the largest in this area, and it is a typical representative of the cone-shaped and tower-shaped karst landform (Liu et al. 2014). Because of the large area of carbonate rocks in the Maolan research area, the karst in this area is extremely developed, and the underground water has a large buried depth. As a result, the water content in the aeration zone is low. Moreover, the soil formation conditions in this area are poor. Hence, several geological environmental problems exist in this area, mainly including three types of soil erosion, rocky desertification, and karst drought (Yzab et al. 2021, Lza et al. 2020).

The Guanshanhu and Weining research areas are urban construction areas, which have high urbanization rates. Human activities have greatly influenced the biodiversity and environmental geological systems, and geological environment problems are continuously emerging, along with the gradual loss of biological habitats. Therefore, the estimated values of these two areas were the lowest among the five research areas. The development status of biodiversity and environmental geological systems has not been coordinated, and the biodiversity system lags behind the environmental geological system. Relevant studies have shown that within a certain period of time, the stress of direct or indirect human activities would lead to dynamic changes of vegetation (Gosselin and Callois 2018).

The expanding urbanization of the Guanshanhu research area has significantly damaged the original natural vegetation, woodland, and basic farmland, and the eutrophication of urban park waters has contributed to the loss or the islandization of biological habitats. This has resulted in a sharp decline of vegetation coverage biological species richness (Xi et al. 2018). In terms of environmental geology, the 
329 Guanshanhu area has been transformed significantly by human activities, and the original landform has greatly changed. Although the geological environment problems that are not conducive to the development of cities and towns have been basically solved, ground surface hardening and the construction of urban rail transit and pipe networks have caused many new geological environment problems, including water depletion and groundwater pollution caused by large-scale urban construction.

The Weining research area is located in the Caohai Nature Reserve. In recent years, human activities, such as urbanization, water conservancy projects, and road construction, have triggered obvious habitat changes in forest, wetland, and water areas, and environmental pollution problems have emerged. In particular, water pollution has greatly harmed amphibians (Xiong et al. 2019). As a result, the water conservation function of vegetation has weakened; the problem of habitat fragmentation has been aggravated; and species richness has been reduced. In addition, invasion of alien species is another non-negligible external factor that has caused a decrease in the biodiversity in the Caohai area (Hughes et al, 2020). After the initial invasion of alien species, such as the Caohai bullfrog or Procambarus clarkii, these species can outcompete local aquatic organisms in the same ecological niche and seize the necessary food and space resources to create competitive advantages due to the lack of natural enemies and the rapid proliferation of their numbers. This phenomenon largely excludes native species, and alien species occupy the ecological niches of native species, thus seriously disrupting local food chains. Once indigenous species have largely disappeared, their role in maintaining the ecological balance is seriously weakened, causing serious damage of the ecosystem and biodiversity of Caohai (Qian and Akay 2020). In terms of environmental geology, the Weining research area has a relatively gentle terrain, good crustal stability, extremely shallow groundwater 
351

352

353

depth, and small flow of common springs. Therefore, no prominent geological environment problems on the whole have emerged in this area (Liu 2014). The geological environmental problems of the Caohai area mainly include four aspects: soil erosion, excessive soil elements, water depletion, and rocky desertification (Kong et al. 2010). Among these problems, rocky desertification has been the main geological environmental problem, and its distribution pattern has shown the characteristics of "the farther away from a city, the wider the distribution area."

\section{Conclusions and suggestions}

In this study, we selected five typical representative areas of Caohai, Chishui, Fanjingshan, Maolan, and Guanshanhu as research targets. We conducted a coupling analysis of their biodiversity and environmental geological systems based on the comprehensive index model and the coupling coordination model. The results showed that the Guanshanhu and Weining research areas belong to urban construction areas with higher urbanization rate, and the biodiversity and environmental geology have been greatly influenced by human activities. Therefore, the coordination degree of the two systems has been poor, and the comprehensive biodiversity index, the comprehensive environmental geological index, and the coupling degree generally were lower than those of the Maolan, Chishui, and Fanjingshan research areas. Among all five areas, Maolan has a typical karst landform, which is prone to soil erosion, rocky desertification, and other problems. Therefore, the comprehensive biodiversity index and the comprehensive environmental geological index of Maolan have been relatively low.

According to the research results and in combination with the practical situation of Guizhou Province, the administrative regions of Guizhou Province can be divided into three zones from the perspective of ecological status: original ecological zones (e.g., the Chishui and Fanjingshan research areas), a zone with fragile ecological environment (e.g., the Maolan research area), and zones affected 
373 by human activities (e.g., the Guanshanhu and Weining research areas). For each zone, policy suggestions are proposed in the following:

In the original ecological zone, protection measures should be continued and strengthened. On the basis of comprehensive biodiversity assessments, areas that are rich in biodiversity or hotspot areas should be designated. In addition, a network of nature reserves, which can be effectively protected, well managed, and connected, should be established on the basis of existing nature reserves. According to the results of risk assessment, areas with rich biodiversity that are sensitive to environmental geological changes in these reserves should be preferentially protected.

In zones with fragile ecological environment, targeted protection measures should be carried out to promote the synchronous development of regional environmental geology and biodiversity. On the basis of environmental geological conditions and according to the topography and landform of key karst zones as well as the structural characteristics of karst water-bearing media, vegetation restoration should be carried out to improve the survival rate of vegetation. When vegetation restoration and reconstruction projects are carried out in rocky desertification areas, it is recommended to carry out vegetation restoration in drainage areas or in areas where cracks and channels are more developed. The vegetation in these areas is more likely to survive and to cope with climatic changes better.

In zones affected by human activities, limiting local human activities is a practical and effective measure for protecting both biodiversity and environmental geology. Relevant control measures should be introduced to strengthen both regulation and protection. Specifically, the major regional strategy, regional coordinated development strategy, the main functional zone strategy, and new urbanization strategy should be continually implemented to guarantee high-quality development. The key ecological zones with a fragile environmental status need to be clarified, and the establishment of a nature reserve 
395

system should be accelerated. Furthermore, the network for biodiversity conservation needs to be improved, and human activities in this space should be reasonably limited to guard natural ecological security boundaries.

\section{Acknowledgments}

This study was supported by the Geological Exploration Fund Program of Guizhou Province (No. 2019-003), the Application and Industrialization Projects of Scientific and Technological Achievements of Guizhou Province (General Project No. 2021-130), the High-score Major Special Projects of the

State Administration of Science, Technology, and Industry for National Defense (No. 88-Y40G35-9001-18/20), the Science and Technology Planning Projects of National High-tech Zone of Guiyang (Nos. GXYF-2017-003 and GXYF-2018-003), the Innovative Talent Team Supporting Projects of Guizhou Academy of Sciences (No. 2019-07), and the Scientific Research Special Fund Projects of Guizhou Academy of Sciences (No. 2019-06).

\section{References}

Antonelli A, Kissling WD, Flantua SGA, Bermúdez MA, Mulch A, Muellner-Riehl AN, Kreft H, Linder HP, Badgley C, Fjeldså J, Fritz SA, Rahbek C, Herman F, Hooghiemstra H, Hoorn C (2018) Geological and climatic influences on mountain biodiversity. Nature Geoscience 11: 718-725.

Bardgett RD, van der Putten WH (2014) Belowground biodiversity and ecosystem functioning. Nature 515: 505-511.

Cai Q, Ji C, Zhou X, Bruelheide H, Fang W, Zheng T, Zhu J, Shi L, Li H, Zhu J, Fang J (2020) Changes in carbon storages of Fagus forest ecosystems along an elevational gradient on Mt. Fanjingshan in Southwest China. Journal of Plant Ecology 13: 139-149. 
Chen HL, Lewison RL, An L, Yu HT, Yang S (2020) Assessing the effects of payments for ecosystem services programs on forest structure and species biodiversity. Biodiversity and Conservation 29: 2123-2140.

Cuomo V, Lanfredi M, Lasaponara R, Macchiato MF, Simoniello T (2001) Detection of interannual variation of vegetation in middle and southern Italy during 1985-1999 with 1 km NOAA AVHRR NDVI data. Journal of Geophysical Research: Atmospheres 106: 17863-17876.

Dong LL, He TB, Liu YS, Shu YG, Luo HB, Liu F (2008) Analysis of the variability of the main physicochemical properties of soils developed from different parent materials (rocks) in karst mountains. Soil Bulletin: 471-474.

Gosselin F, Callois JM (2018) Relationships between human activity and biodiversity in Europe at the national scale: Spatial density of human activity as a core driver of biodiversity erosion. Ecological Indicators 90: 356-365.

Guo Y, Ren B, Dai Q, Zhou J, Zhou J (2020) Habitat estimates reveal that there are fewer than 400 Guizhou snub-nosed monkeys, Rhinopithecus brelichi, remaining in the wild. Global Ecology and Conservation 24: e1181.

Hu A, Wang J, Sun H, Niu B, Si G, Wang J, Yeh C, Zhu X, Lu X, Zhou J, Yang Y, Ren M, Hu Y, Dong H, Zhang G (2020) Mountain biodiversity and ecosystem functions: interplay between geology and contemporary environments. The ISME Journal 14: 931-944.

Huang S, Meijers MJM, Eyres A, Mulch A, Fritz SA (2019) Unravelling the history of biodiversity in mountain ranges through integrating geology and biogeography. Journal of Biogeography 46: $1777-1791$.

Hughes KA, Pescott OL, Peyton J, Adriaens T, Cook EC, Key G, Rabitsch W, Tricarico E, Barnes D, 
Jiang Z, Liu H, Wang H, Peng J, Meersmans J, Green SM, Quine TA, Wu X, Song Z (2020) Bedrock geochemistry influences vegetation growth by regulating the regolith water holding capacity. Nature Communications 11: 2392.

Kong FC, Yang RD, Lin SJ (2010) Analysis of the Evolution of Karst Environment of Weining Region,Guizhou Province,West China: A Proof from the Sediment Evolution of Lake Caohai

Lang HL, Long CL (2012) Relationship between species diversity and soil factors in karst forests of

Li YB, Wang SJ, Li RL (2004) Differences in the natural characteristics of karst ecosystems in different geological contexts - the case of Maolan and Huajiang. Earth and Environment 32: 9-16.

Liu F, Wang S, Luo, H, Liu YS, Liu HY (2008) Microhabitats and soil heterogeneity in karst forest ecosystems. Journal of Soil Science 45: 1055-1062.

Liu P (2014) Research on Karst Hydrogeological Conditions and Karst Water Resources Evaluation in Caohai Area, Weining, Guizhou.: Chengdu University of Technology.

Liu SL, Dong YH, Sun YX, Shi FN (2019) Analysis of priority areas in mountains, water, forests, fields, lakes, and grasses based on ecosystem service enhancement - Guizhou Province as an example. Journal of Ecology 39: 8957-8965. 
Liu ZQ, Xiong KN, Li GC, Xiao SZ, Wang LY, Wang HS, Luo D (2014) Geomorphological value and contribution of Huanj iang Karst Extension to the South China Karst World Heritage. China Karst 000: 64-76.

Lza B, Xwa B, Zwa B, Xza B, Cheng C, Hla B (2020) The challenge of soil loss control and vegetation restoration in the karst area of southwestern China. International Soil and Water Conservation Research 8: 26-34.

Ott RF (2020) How Lithology Impacts Global Topography, Vegetation, and Animal Biodiversity: A Global-Scale Analysis of Mountainous Regions. Geophysical Research Letters 47.

Qian FK, Wang WW, Wang QB (2018) Quantifying the synergistic relationship between natural quality of cropland and stand conditions based on coupled coordination model. Journal of Agricultural Engineering 34: 284-291.

Qian JJ, Akay E (2020) The balance of interaction types determines the assembly and stability of ecological communities. Nature Ecology \& Evolution 4: 356-365.

Sheng MY, Xiong KN, Cui GY, Liu Y (2015) Plant diversity and soil physicochemical properties in karstic desertification areas of Guizhou. Journal of Ecology 35: 434-448.

Wang J (2013) Study on the relationship between geological background and plant diversity in Gongbu Nature Reserve, Tibet. : Chengdu University of Technology.

Wang K, Song HZ (2003) A comparative analysis of three objective weight assignment methods. Research in Technology Economics and Management: 48-49.

Wang R, An YL (2014) Study on biodiversity and habitat sensitivity in Guizhou Province. Journal of Guizhou Normal University (Natural Science Edition) 32: 28-33.

Wang R, An YL, Wang PB, Ma LR (2014) Study of biodiversity hotspots in Guizhou Province. Soil 

conservation to prevent habitat losses to agricultural expansion. Nature Sustainability 4: 314-322.

Wilson E, Ehrlich PR (1991) Biodiversity Studies: Science and Policy. Science 253: 758-762.

487

Wu P, Cui Y, Zhao W, Shu D, Hou Y, Ding F, Yang W (2019) Characteristics of soil stoichiometric in natural restoration process of Maolan karst forest vegetation, southwestern China. Journal of Beijing Forestry University.

Xi X, Xie Y, Ke Q, Luo Z, Wang X (2018) Detecting the response of bird communities and biodiversity to habitat loss and fragmentation due to urbanization. The Science of the Total Environment 624: 1561-1576.

Xiong JX, Chen DL, Peng BF, Deng ST, Xie XM (2014) Spatial and temporal variation in the coupled coordination of ecological carrying capacity systems in the Dongting Lake area. Geoscience 34: 1108-1116.

Xiong W, Ni P, Chen Y, Gao Y, Li S, Zhan A (2019) Biological consequences of environmental pollution in running water ecosystems: A case study in zooplankton. Environmental Pollution 252: 1483-1490.

Yu YH, Xiao WP, Yan LB, Yu LF, Huang ZS (2015) Species diversity of forest plant communities in the upper Chishui River. Guangdong Agricultural Science: 142-145.

Yzab C, Yj A, Zzab C, Zy A (2021) Global trends in karst-related studies from 1990 to 2016: A bibliometric analysis. Alexandria Engineering Journal 60: 2551-2562.

Zhang HL, Cai J, Xia XL (2018) Analysis of coupled coordination between erosion management benefits and ecological agriculture development. Journal of Agricultural Engineering 34: 162-169. 
505 Zhao WQ, Wu KH, Su WC, Lu L (2011) Comprehensive evaluation and analysis of biodiversity in 506 Guizhou Province. Soil and Water Conservation Bulletin 31: 171-174.

507 Zhou YR (2000) Land use in Guizhou Province. In: Twenty Years of Land Science in China Proceedings of the Celebration of the 20th Anniversary of the Chinese Land Institute. 
Figures

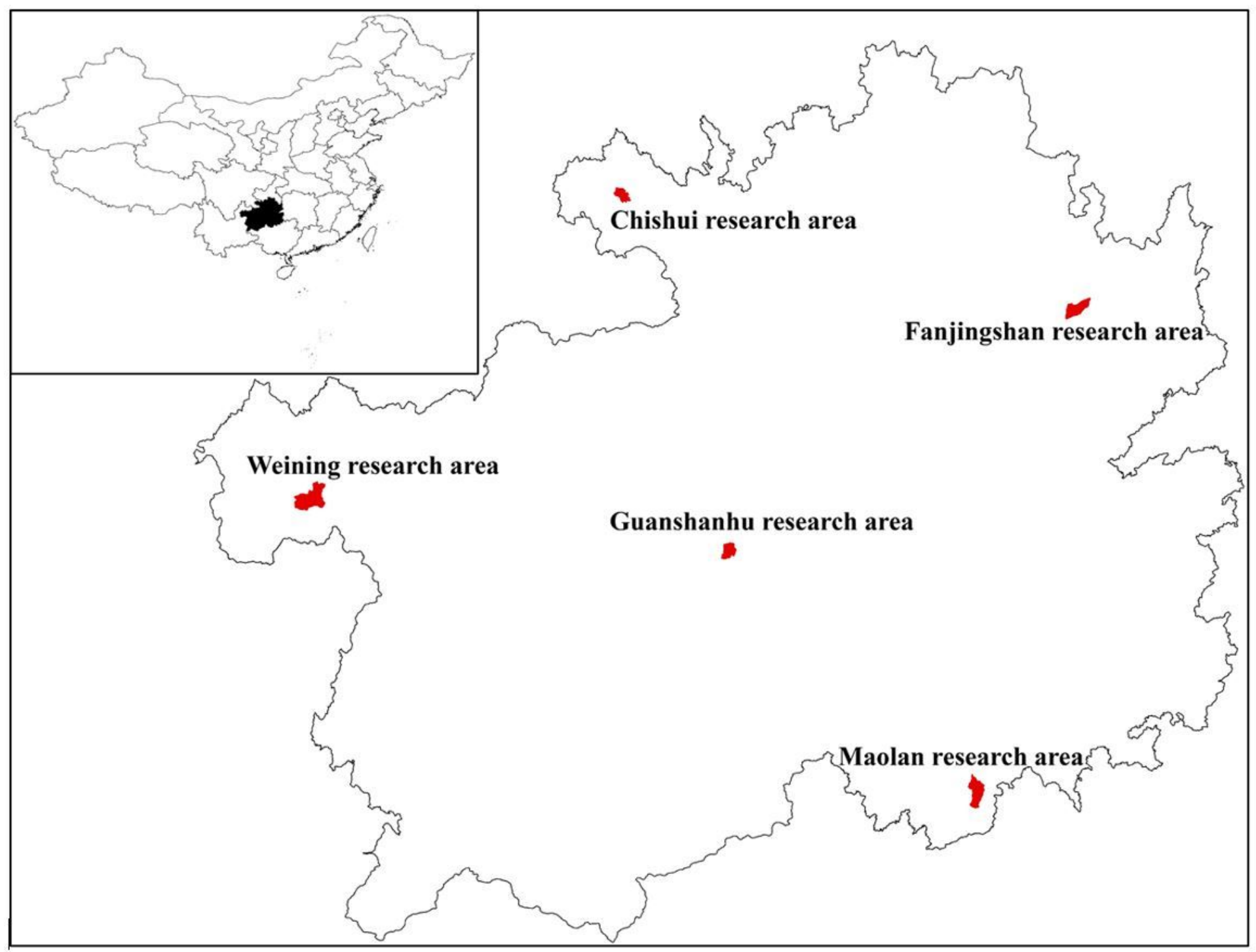

Figure 1

Geographical location map of research areas. 


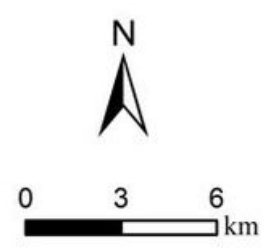

(a)

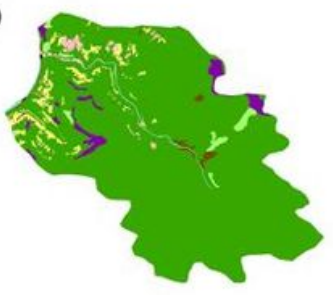

(b)

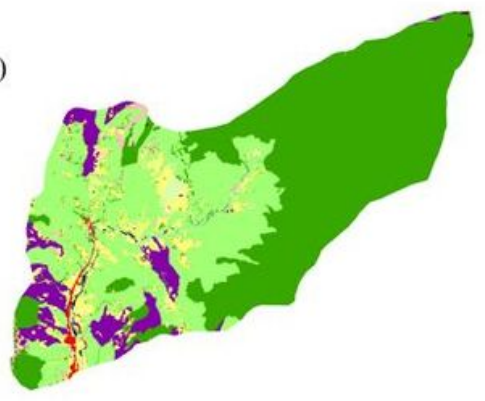

(c)

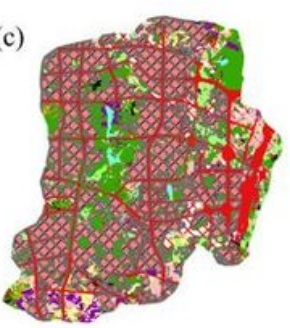

(d)

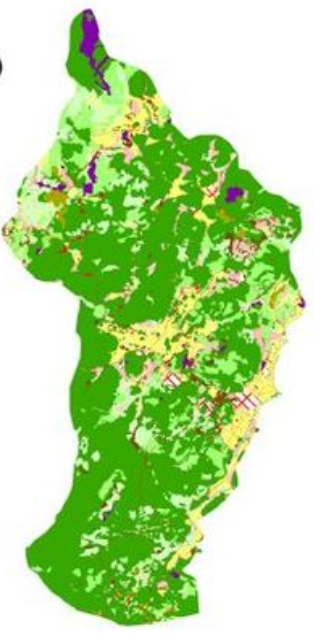

(e)

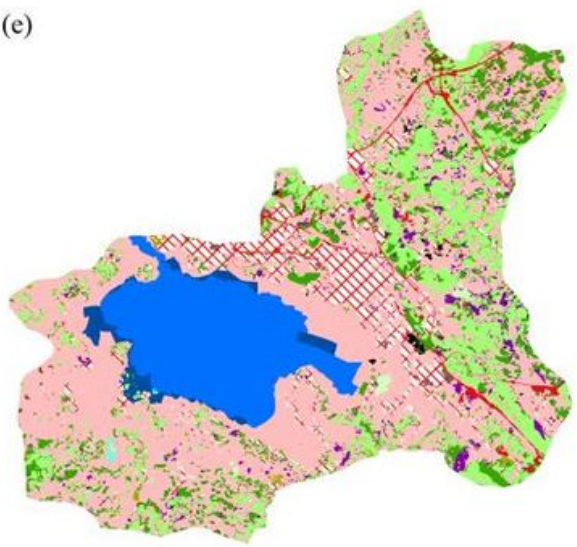

Legend

W. towns and villages artificial forest

urban land

industrial and traffic land

dry land

reservoir and pit-pond paddy field

river

marsh

$\square$ lake

shrubbery

grassland with shrubs

meadow

bare land coniferous forest mixed forest broad-leaved forest

\section{Figure 2}

The spatial distribution of ecosystem type in the research areas: (a) Chishui, (b) Fanjingshan, (c) Guanshanhu, (d) Maolan, and (e) Weining. 
Q The comprehensive index of environmental geology

$\square$ The comprehensive index of biodiversity

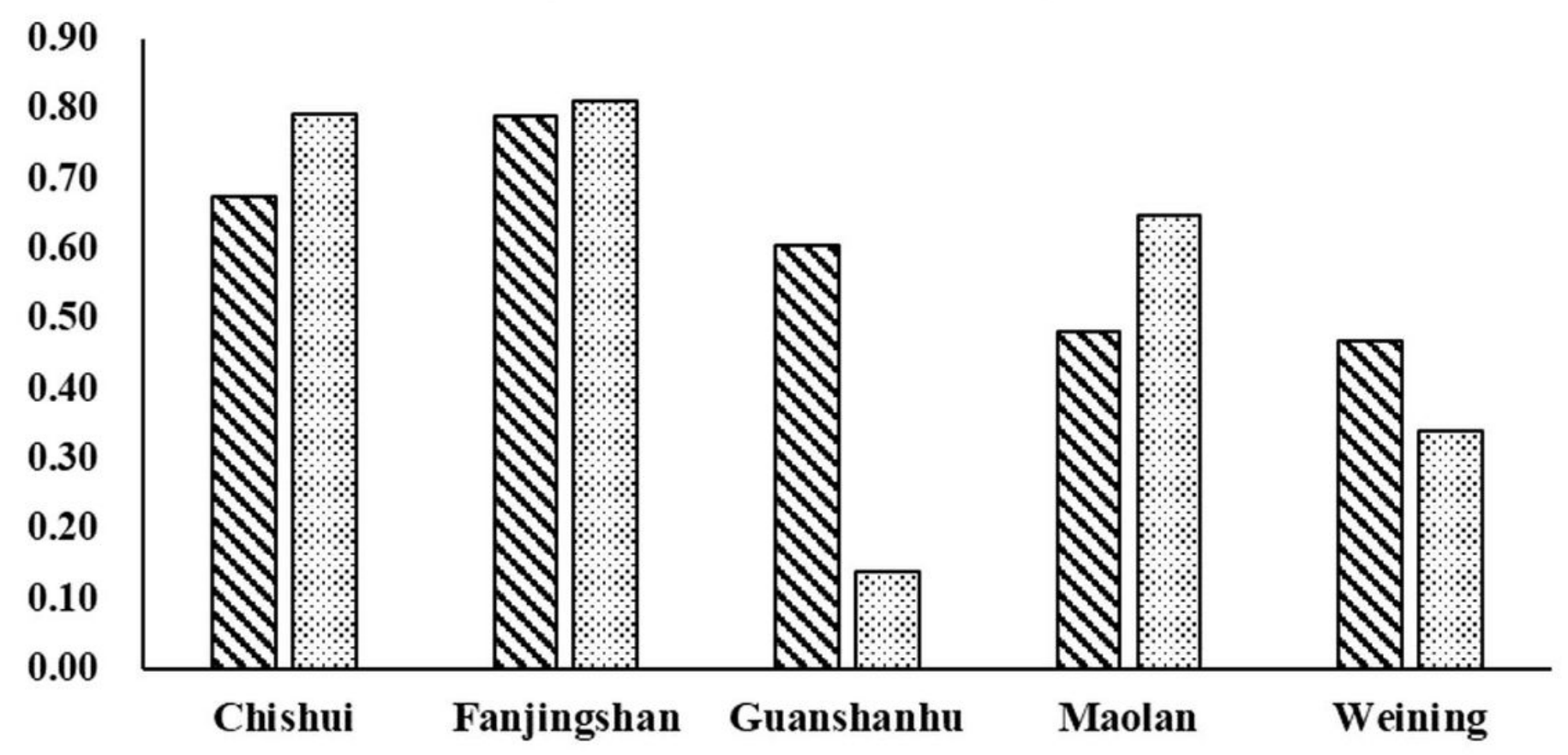

Figure 3

Comparison of comprehensive index of biodiversity and environmental geology in five research areas. ๑Coupling degree $\square$ Coordination degree

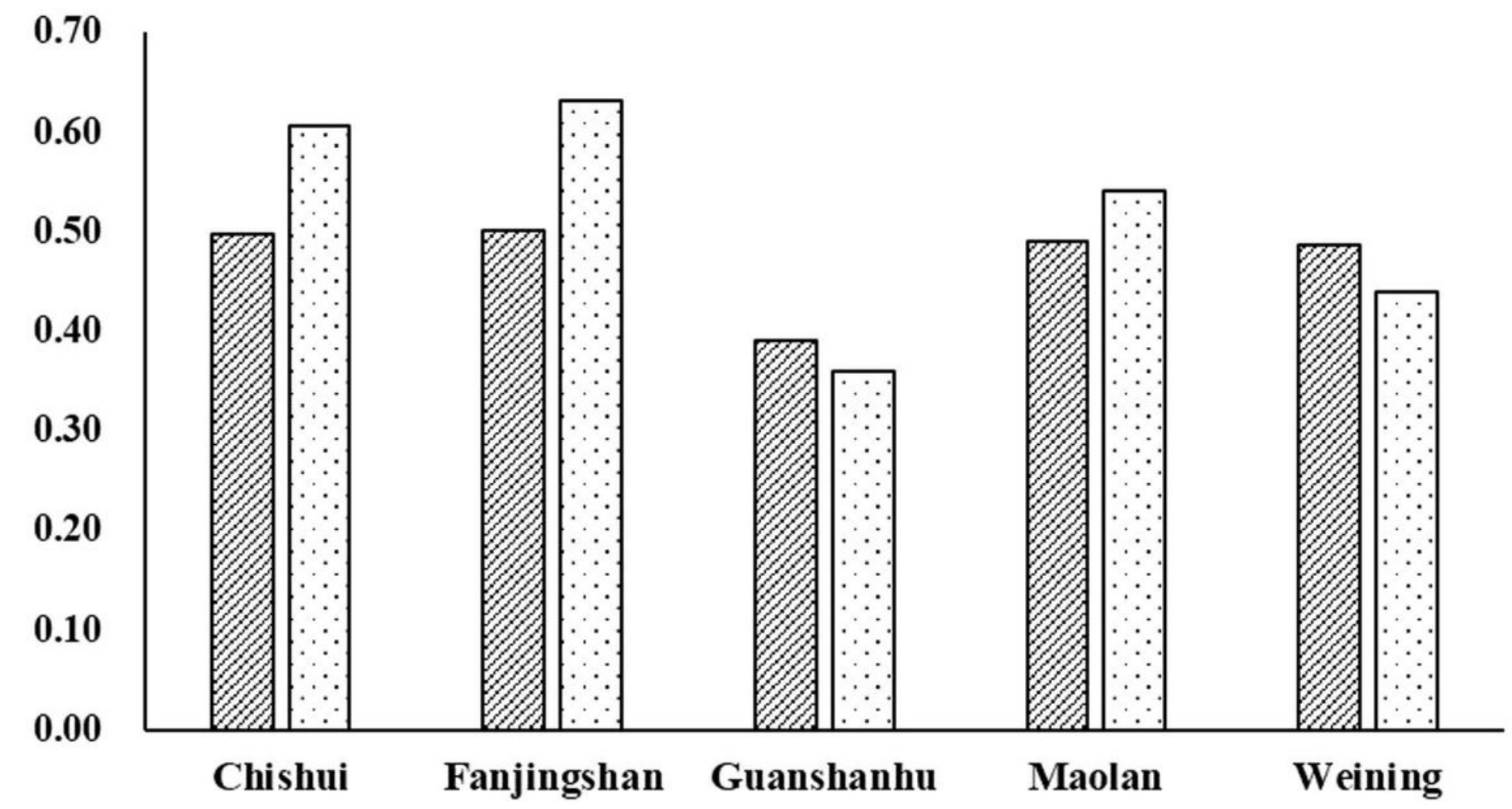


Figure 4

Comparison of coupling degree and coordination degree in five research areas. 